\title{
Reconsidering Scenic Beauty
}

\section{ARNOLD BERLEANT}

Professor Emeritus of Philosophy

Long Island University

Email:ab@contempaesthetics.org

\begin{abstract}
Attempts to justify the objectivity and universality of aesthetic judgment have traditionally rested on unsupported assumptions or mere assertion. This paper offers a fresh consideration of the problem of judgments of taste. It suggests that the problem of securing universal agreement is false and therefore insoluble, since it imposes an inappropriate logical criterion on the extent of agreement, which is irrevocably empirical. The variability of judgments of taste actually forms a subject ripe for inquiry by sociologists, psychologists, historians and anthropologists, as well as by aestheticians. Scenic beauty provides a vivid test for the variability of these judgments.
\end{abstract}

\section{KEYWORDS}

Agreement, judgments of taste, universality, variability 


\section{ARNOLD BERLEANT}

\section{THE PROBLEM}

Judging scenic beauty raises problems for aesthetics that aestheticians have long faced nobly but by which they have been ignobly defeated. This can, in fact, stand as a representative case for problems concerning judgments of taste en tout. It is often assumed that judgments of taste rest on the objectivity of aesthetic value and that ideally these judgments should exhibit universal agreement. The fact that such agreement has never been reached seems not to have deterred philosophers from claiming that it is necessary in order for any such judgment to be valid. I want to propose that, on the contrary, judgments of taste are not only not universal but that universality is neither necessary nor desirable, for it unduly constrains the range of aesthetic judgment.

Scenic beauty offers an attractive entrée into this problem, for its appreciation is widespread. Delight in the beauty of landscape cuts across educational, cultural and intellectual differences and at the same time exhibits a high degree of concurrence. Granted there have been historical differences in the appreciation of natural scenery, especially in the case of mountains and forests, once considered ominous and threatening and more recently majestic and noble. And the same transformation of taste seems now to be happening in the appreciation of swamp, marsh and desert landscapes. Although at various times common agreement has been widespread, universality remains elusive. ${ }^{1}$

The attempt to justify the objectivity and universality of judgments of scenic beauty rests on the conviction that such judgments of taste require universal agreement. This desideratum has not been borne out by empirical studies of landscape preference but it nevertheless remains the normative ideal. I would like to examine this issue afresh, not by appealing to empirical research on landscapes preference, which requires its own critical appraisal, but by reconsidering the philosophical issue. ${ }^{2}$ I want to propose that the requirement of universality is ungrounded and that it engenders a philosophical problem that is false and therefore insoluble. What remains for philosophic consideration are matters of a different kind that are more tractable and lead to a different kind of resolution.

The question at issue concerns the range of normative judgments that different individuals make of natural beauty or of art. The object of appreciation is presumably the same for everyone, yet the value put on it is never unanimous but varies for different individuals and may even change for the same individual on different occasions. Regardless of where the locus of beauty is considered to be, whether a property of the object or a sentiment 


\section{RECONSIDERING SCENIC BEAUTY}

in the subject, conventional logic carries the presumptions of objectivity and universality, and insists that judgments of the same object should agree. The reasons for this insistence vary. Sometimes they rely on the claim that value is objective and that, if we recognise and identify it properly, our judgments would concur. Often they rest on the belief that humans are basically similar and have similar capacities for aesthetic appreciation, and since our appreciation is directed toward the same object, our judgments may be expected to agree.

The expectation, then, is of common agreement, yet the facts are otherwise and the problem lies in this disparity. Both Hume and Kant faced this issue and their answers, though different, show remarkable similarities. Let me start by recalling these classic accounts, not to critique them as representative models, but because they are useful in locating the salient features of the issue.

Hume's discussion of the judgment of taste is widely regarded as definitive. Briefly stated, Hume distinguished between judgment and sentiment. Sentiment, he recognised, is never wrong since it refers only to itself. If viewing a landscape from a hilltop gives us a thrill of pleasure, the pleasure is real and incontrovertible. If our companion is bored and would rather return to the tour bus and view the landscape on the TV monitor, that feeling is equally genuine. As Hume put it, 'All sentiment is right; because sentiment has a reference to nothing beyond itself, and is always real, wherever a man is conscious of it. ${ }^{3}$ It is different, however, if we ascribe beauty to the landscape, for then we are referring not to our feelings but to some thing beyond, and our judgment must conform to that object. 'Among a thousand different opinions which different men may entertain of the same subject, there is one, and but one that is just and true: the only difficulty is to fix and ascertain it. On the contrary, a thousand different sentiments, excited by the same object, are all right; because no sentiment represents what is really in the object. ${ }^{4}$ By opinion Hume meant statements of fact, and for him, beauty does not lie in the object but rests only on our sentiment. However, there are qualities in objects that excite that sentiment, and the competent critic can identify and evaluate those qualities.

It may be sufficient to say that the judgment of a critic who has keen sensibilities, wide aesthetic experience, and relevant knowledge is the most trustworthy, and that the judgments of such critics are likely to agree. ${ }^{5}$ Nonetheless, according to Hume, differences will result from 'the different humours of particular men' and 'the particular manners and opinions of our age and country'. However, ' $[t]$ he general principles of taste are uniform

in human nature' ${ }^{6}$ Hume thus leaves us with the possibility of widespread 


\section{ARNOLD BERLEANT}

agreement but at the same time with the recognition that residual differences are unavoidable but explainable.

Kant's dissatisfaction with Hume is well known, and he offered an alternative that provided a more affirmative answer to the question of establishing agreement in aesthetic judgment. For Kant the judgment of taste is not cognitive but aesthetic, and this means that it cannot avoid being subjective. ${ }^{?}$ Like Hume he believed that such judgments may refer to an object but that they rest on pleasure or pain, which signifies nothing in the object but only the feeling that the object evokes in the subject.

Kant nevertheless attempted to justify judgments that, though subjective, are universal, and he did this mainly by appealing to a common sensibility, a sensus communis. While such judgments cannot be cognitive, their universality may nevertheless be claimed on the basis of this sensus communis. This, he thought, allows for what he called a 'subjective universal'. But while there may be some feelings and responses toward the same object felt by most people, the extent to which that is so in individual cases is an empirical question and true universality is impossible to attain. What Kant was left with, then, and all that was possible, was the claim of universality of a sort, 'subjective universality'.

Despite their radical differences, both Hume and Kant shared some key ideas. Neither claimed cognitive universality for judgments of taste. Hume seemed to think that universality was theoretically possible since judgments are of the same object, but that the conditions for attaining it could not be met since we can never overcome the subjectivity of taste. Such judgments are unavoidably variable, and variability is a condition of the situation. The challenge is to identify the causes of residual disagreement. Kant introduced that guarantor of what cannot be proved, a deus ex machina, by appealing to a sensus communis, a pure construction, to establish human universality. Whether this condition of indeterminacy can be overcome rests on how far one is willing to travel beyond the experience of beauty on an article of faith: Hume not at all; Kant gingerly but very far.

Hume and Kant exhibited common features in the ways we often understand the problem of taste, and they illustrate traditional ways of adjudicating the problem. To reconsider the issue we need to question certain presumptions pervasive in the philosophical tradition. This will make it possible to consider alternatives that will dramatically re-shape our understanding of such judgments. 


\section{RECONSIDERING SCENIC BEAUTY}

\section{PRESUMPTIONS OF TASTE}

Let us approach this issue differently by questioning an assumption common to such discussions as this. It is an idea that Hume and Kant undoubtedly took for granted, as many still do today, and it appears in the very structure of the problem. For them the problem of taste is that the difference in our judgments rests on the disparity between the experience of beauty, and hence the subjectivity of appreciation, and the independence of the normative object toward which our judgment is presumably directed. This division structures the issue in such a way that the difference cannot be reconciled: it is difficult for feeling to conform to logic. More than this, disappointment at not succeeding is unavoidable because the underlying presumption is that an objective judgment of its beauty must be both possible and desirable since there is an independent object of appreciation.

Such reasoning is, however, fatally circular because it is doubly assumptive and consequently doubly false. Judgments must concur because knowledge must be universal, people are similar, and so is the object of their appraisal. But such universality cannot merely be assumed or claimed: it is precisely what needs to be proved. People's perceptual acuity varies, their capacity for focused attention is different, and even more variable are their experience and education. In the light of such facts, the extent of actual agreement is surprisingly often considerable, even though not universal. Variable, too, is the scenic object. Not only does a scenic view change constantly with every breath of breeze, every cloud movement, as well as the changes of light and shadow caused by the continuous movement of the sun along its trajectory. Less noticeable, perhaps, but even more significant is the transitory relation of the observer to the scene, where mood, disposition, and slight shifts in stance and location cause alterations in the scene, compounding its variability. As there is no stable object, there is no stable viewer.

Whatever reconciliation of the disparity in judgment that thinkers following Hume and Kant can claim actually rests on several articles of faith. For Hume it was the assumption that there is an independent object toward which individual experiences veer and that, if they conform to the traits of that object, the judgments must concur. That they do not always agree he attributed to differences in sensibility, customs and experience. ${ }^{8} \mathrm{Kant}$ 's appeal to a sensus communis is to an unsupported assumption, a pure fabrication founded on an assumed intellectual necessity and limited evidence and not on observation. It is a concept constructed out of air.

This situation exemplifies John Dewey's observation that the problems of philosophy are for the most part the problems of philosophers and not 


\section{ARNOLD BERLEANT}

the problems of other people. It is not the first time that philosophy has tied itself up in knots of its own making, and this is nowhere more evident than in attempts to objectify the world. We persist in following Kant in thinking we can speak to some degree meaningfully of what lies beyond human perception. William James recognised the limitation inherent in the notion of an independent objectivity when he noted 'the general law of perception, which is that whilst part of what we perceive comes through our senses from the object before us, another part (and it may be the larger part) always comes out of our own mind'. ${ }^{9}$ The contemporary Chinese aesthetician Wangheng Chen nicely expressed the extent of the human contribution when he observed that 'Fundamentally, beauty, including natural beauty, is a product of the humanisation of nature'.${ }^{10} \mathrm{We}$ might even consider emulating Kant's understanding, which unfortunately he himself did not follow consistently, and recognise that what lies beyond perception utterly eludes human knowledge. The wisdom of the East may express this best of all: 'The greatest beauty exists in nature (sky and earth), but at the same time it keeps silence. ${ }^{11}$ And even the physicist Werner Heisenberg noted that 'When we speak of a picture of nature...we do not actually mean any longer a picture of nature, but rather a picture of our relation to nature'. ${ }^{12}$

When it comes to one's basic grasp of the order of things natural and social, the process of emancipation is even more difficult. The literature on ideology is far exceeded by the literature of ideology. That is one reason why, in the industrialised West, the separations that divide things are so pervasive and powerful. The world we have constructed is a world of discrete objects separated from one another, objects and events that, like Leibniz's monads, are related only externally. It is a world of discrete individuals, a world of integers. And to call a world of independent, external objects 'realism' is to beg the question, for beneath this monadic order lies the most basic separation of all, our Cartesian inheritance of subjective consciousness insulated from an objective world. This is a division comfortable because it is customary. The fact that this imposes a template on experience is overlooked.

Many things lead us to question this claim to adequately reflect the world. A philosophical critique of Cartesianism demands its own inquiry, but it may be worth looking at evidence that suggests an alternative. A body of related data may weigh more heavily than an extended argument. Here, then, are several considerations. 


\section{RECONSIDERING SCENIC BEAUTY}

\section{AN EMPIRICALLY-GROUNDED AESTHETICS}

Theoretical developments in psychology and sociology over the last century have profound significance for aesthetic theory. The accounts of perceptual experience they offer are directly relevant, since aesthetics is itself grounded in experience. And they contribute to a reconsideration of taste. Let me begin with etymology.

The etymological reason is definitive but not conclusive. It is well known that the term 'aesthetics' is a transliteration of the Greek aisthēsis, whose literal meaning is perception by the senses, and that the discipline of aesthetics was established by Baumgarten, who defined 'aesthetics' as 'the science of sensory knowledge directed toward beauty' and 'art' as 'the perfection of sensory awareness'. ${ }^{13}$ The very identity of aesthetics rests on the centrality of sense perception: perceptual experience as the basic dimension of appreciation, perceptual experience as underlying the creative process (pace Croce and Collingwood), and perception as central for the practice of criticism insofar as this directs appreciation and judgment to the experience of art objects. All this signifies that the meanings, concepts and theoretical structures of aesthetics, many of which originated in speculative epistemology and metaphysics, may be poor guides in a field that is fundamentally experiential. This has critical relevance to problems involving aesthetic judgment, particularly judgments of taste.

Coming at this from other directions, we need to recognise what psychologists of perception have long noted, that humans' relation to things is not a relation between discrete and self-sufficient entities. On the contrary, just as people impose themselves on things, so, too, do things exercise an influence on people. Among the classic contributions to psychological aesthetics are Lewin's field theory and his identification of invitational qualities; and J.J. Gibson's theory of affordances, features in an environment that encourage certain behaviour. Much has been done by the successors to Lewin and Gibson in developing and elaborating their ideas and, while these views may not as yet have gained universal assent, they are widely recognised as influential. Equally germane is the development over the past century of the sociology of knowledge, which has shown convincingly how social and cultural factors underlie the very conceptual structures in which we formulate and organise our knowledge of the world. ${ }^{14}$

Sociological analysis also contributes to the empirical study of aesthetic judgment. One of the most forceful recent critics of aesthetic theory is Pierre Bourdieu. His extended study, Distinction: A Social Critique of the Judgement of Taste, develops at length the thesis that '[s]ocial subjects, classified 


\section{ARNOLD BERLEANT}

by theirclassifications, distinguish themselves by the distinctions they make, between the beautiful and the ugly, the distinguished and the vulgar, in which their position in the objective classifications is expressed or betrayed' ${ }^{15}$ Bourdieu applied this analysis of taste widely and with special effectiveness to Kant: 'Kant's analysis of the judgment of taste finds its real basis in a set of aesthetic principles which are the universalisation of the dispositions associated with a particular social and economic condition. ${ }^{16}$ Thus not only is taste variable because of social class differences; its very philosophical consideration finds its formulation shaped by similar influences. In fact, Bourdieu claims, Kantian disinterestedness, the basis for the discrimination of the pure pleasure afforded by beauty from interested enjoyment, indeed the Critique of Judgment itself, is based on a sense of distinction that marks an invidious social relation. ${ }^{17}$

But there are more empirical data to be considered, for in addition to psychological and sociological evidence, it is now widely recognised that agreement is widely grounded on culture, and here the comparative study of aesthetics is important. In one such study, the anthropologist Robert Plant Armstrong describes art as the work of 'affecting presence'. He abandons the ethnocentrically identified assumption that all works we call 'art' possess the same aesthetic properties and that these underlie our judgments of beauty and virtuosity. The presumption of such a universal aesthetic, he argues, is challenged by non-Western cultures that exhibit how observable aesthetic beliefs and behaviour are as variable as institutions and every other social construction. Aesthetic values in these cultures do not rest on beauty but derive from what Armstrong calls the embodiment and management of powers. Using African and Upper Paleolithic work, he argued that concepts of beauty, truth and excellence have little to do with the inherent cultural value of an object, and he developed an aesthetic typology that integrated human consciousness and its reification as art. Art thus becomes the work of 'affecting presence' embodying in mythic configurations the mammalian, human, cultural and autobiographical features of consciousness. The presence that is established is affecting because of the power ascribed to myth, and this presence determines the realm of the aesthetic. ${ }^{18}$

It is also important to include here philosophical developments that offer alternative structures for understanding humans' standing in the world. Among these we can include Maurice Merleau-Ponty's efforts to identify the continuities that express the embeddedness of humans in the world. These include such ideas as the flesh of the world, as well as the 'chiasm', which identifies the reciprocity that permeates human relations with self, other living beings, and the features and objects of the natural world. Similar efforts to 


\section{RECONSIDERING SCENIC BEAUTY}

formulate these connections were made by Gilles Deleuze and Félix Guattari when they spoke of the experience of 'becoming' as a desubjectification that precedes the distinction of self and object. I have long been working with the concept of an aesthetic field, which identifies and explicates the holistic situational context of aesthetic experience. ${ }^{19}$

General understanding usually lags generations behind major scientific developments, and philosophic theory is no exception. Scholarly consciousness (not to mention popular understanding) is still struggling to accommodate the implications of relativity theory and quantum mechanics, and of the qualifications of scientific knowledge demanded by Heisenberg's principle of indeterminacy and other such revolutionary cognitive developments. The implications of conceptual changes like these have powerful consequences for aesthetic conventions. ${ }^{20}$ These developments carry conceptual changes that profoundly affect the place of humans and the human world. Nothing is more fundamental and nothing has greater consequences for aesthetic theory, and conventional views of aesthetic experience cannot accommodate such a change. On one side of the ledger, analytic aesthetics focuses on the art object, or sometimes, as Monroe Beardsley did, on the aesthetic object: its qualities, its features, its historical setting, its relations with other objects, its actions and effects and the actions and effects of other things on it, and, perhaps centrally, the critical statements - descriptive, interpretative and evaluative - we make about such objects. ${ }^{21}$ Such objects occupy a place in an orderly world and the task of aesthetics is to demarcate that place clearly. Science figures here as a model of conceptual clarity and epitomises the cognitivist orientation of analytic aesthetics.

On the other side, insofar as we can identify distinct alternatives, are traditions associated with what is commonly called continental aesthetics, movements that include aspects and influences coming from phenomenology, hermeneutics, post-structuralism and post-modernism, with some influences from critical theory, feminism and the philosophy of culture. Art here tends to be seen as 'the sensuous embodiment of conscious enquiry', affecting our understanding of how we relate and 'interact with other objects and minds' ${ }^{22}$ Emphasis is placed on the body, bodily sensation and our senses, and on the historical and cultural influences that pervade our understanding. Continental aesthetics embraces diverse movements, certainly, but a feature frequently found in this work is a focus on subjectivity, consciousness and inter-subjectivity in the process of aesthetic understanding.

These are trends in aesthetic thought and do not define the parameters of the work of any specific scholar, nor are they sharply divided. Differences occur in emphasis and approach, and trends and resemblances are present 


\section{ARNOLD BERLEANT}

and apparent both within and between diverse approaches. Yet as conceptual orientations, both suffer from partiality and incompleteness. The philosophical investigations of Merleau-Ponty, Deleuze, Guattari and other more recent scholars, together with critical insights from psychology and sociology, offer a still different view of the world of aesthetic understanding. This is a vision that is able to accommodate both the consistency and variability in aesthetic perception. How can we best conceptualise this understanding of aesthetic judgment? Let us consider an account of aesthetic experience that is compatible with this body of empirical data and provides a more comprehensive understanding of judgments of taste.

\section{AESTHETIC ENGAGEMENT AND AESTHETIC NATURALISM}

The concept of aesthetic engagement signifies human embeddedness and active participation in the experience of appreciation. ${ }^{23}$ Rather than adopting a sense of distance in contemplating a landscape or an art object, engaged appreciation encourages a close involvement characterised by experiential reciprocity. In place of a separation between viewer and landscape, it affirms a continuity that is both physical and experiential. Aesthetic appreciation encourages such personal engagement. While true in art, this experience is both encouraged and especially vivid in landscape appreciation, where it becomes not only visual but overtly somatic. Such appreciation is an experience of physical presence that is implicitly or overtly participatory, projecting somatic awareness by virtual projection into the landscape or by actual movement through by it.

When we make perceptual continuity central in aesthetic appreciation, we transform the problem of aesthetic judgment. In place of a dualism of viewer and landscape, perceiver and object, each of the pair reciprocates the other, and we have a situation in the form of an aesthetic field characterised by an actively perceiving human participant within and part of a sensory environment. Every perceiver contributes to the situation, not only through perceptual activity, but with the invisible dimensions of past experience, memory, knowledge and conditioning - the whole range of personal and cultural factors that colour our active sensory experience, whether or not we are aware of it. This structural order of the aesthetic field is informed by the character of particular occasions.

From such occasions of aesthetic appreciation, judgments of aesthetic value are formed, and we cognise these aesthetic events in the form of aesthetic judgments. Beauty then becomes the positive aesthetic designation of 


\section{RECONSIDERING SCENIC BEAUTY}

a particular aesthetic field, and the sublime a different, distinctive, usually positive designation. Of course each situation has individual features that vary with time, place and participants, and our judgments of value are similarly variable. To the extent that occasions and participants share significant features, the aesthetic judgments formed of them will tend to agree. But time, experience and individual variability introduce irreducible differences, and because no two occasions are exact duplicates, judgments of them will thus rarely be unanimous. From an empirical standpoint, the variability of aesthetic judgment is no disability; it simply reflects the motile conditions of appreciative experience. Only when a cognitive template is imposed on such experience is variability considered a defect. Universality is a logical desideratum, not an empirical one.

At the same time, the actual extent of variability is not infinite. Despite social and psychological dissimilarities, humans' biologically based sensory capacities are very much alike. To the extent that these resemblances are intensified by a common culture, agreement will be the greater, but where there is no common culture, there will be less agreement. In all this, however, disruptive factors lie in the very differences and influences that Hume noted. Insofar as experience and knowledge are added to interest and perceptual sensitivity, these will be reflected in expert judgment. And variation in expert judgment is no disability: like all judgment, this is itself open to reflective deliberation and empirical testing.

This view carries important implications, not only for landscape appreciation but for judgments of taste in general. The experience of landscapes, the experience of nature more generally, identifies a relationship even more than a relation, a situation that finds the human embedded within and part of every experiential context. Thus in speaking about engaging landscapes, we identify not only an aesthetics of environment but also a metaphysics. How we experience landscapes involves not only an inner feeling or a purely sensory event or a particular kind of aesthetic object. It is rather how we live in the world and the kind of world we inhabit.

But how we live in the world and how we think and talk about it are often quite different from each other. Formed by a cultural environment, we imbibe a consciousness of its order as part of our growing awareness. Even in a society that allows discussion and debate, the possibility of a critical reconsideration of its parameters of thought is slow and uneven, even more perhaps than open reflection on religious or moral beliefs. Under relatively stable conditions, when cultural change moves imperceptibly, reaction to such convictions, internalised along with other customs, habits and ideological configurations during the early decades of life, rarely emerges for 


\section{ARNOLD BERLEANT}

re-evaluation to the point of emancipation or even of conscious acceptance. Even violent opposition may not be a sign of emancipation from a cultural ideology but merely a sign of negation. It is difficult to combine impartiality and emotional neutrality with intellectual independence in order to identify and critically consider customary moral and religious beliefs and coolly appraise alternatives.

Understanding judgments of taste in a way that recognises the influence and force of invitational qualities, affordances, reciprocity, engagement and the pervasive influence of culture offers not only a logical alternative but a living alternative, one that provides an empirical grounding for critical reconsideration. Such an account can accommodate the facts of appreciative experience and judgment without feeling distress over their variability. It is based on perceptual experience rather than on the requirement to conform to an a priori logical or epistemic criterion of universality.

The extent of agreement is thus an empirical matter. It is no surprise that its scope is considerable, even though far from universal, considering the biological and cultural commonalities that bind people together. Ludwig Wittgenstein made a similar point when he averred that "It is ... only where there is "agreement in ... form of life" that there can be shared understanding of the meanings of words, gestures, practices .... ${ }^{24}$

\section{CONCLUSION}

I am not proposing that we abandon aesthetics altogether, only that we reconsider the kind of contribution that philosophy is able to make. Can we continue to maintain that beauty is something objective and universal, independent of empirical evidence? If so, then we risk being circular. On what other grounds can we retain the belief in the objectivity of beauty? Metaphysical? Mere assertion has no claim to acceptance. Whatever contribution philosophy can make must be germane to the conditions of its inquiry.

It is not necessary to fully accept Bourdieu's reduction of taste to invidious social distinctions to acknowledge the force of his basic claim. Philosophy, despite its origins and conduct as a discipline seeking and embodying eternal truths, cannot rise above its cultural origins. It cannot legislate itself out of its social and historical context and it is no more immune to such conditions than any other study. What is true for philosophy is especially applicable to aesthetics, a discipline grounded in perceptual experience, where we encounter a plurality of judgments of taste as varied as the conditions under which they are made. Distinctions of taste, like all judgments of experience, 


\section{RECONSIDERING SCENIC BEAUTY}

are subject to the multiple somatic and cultural forces that influence them. Any single factor, including social class, is unlikely to wholly determine the judgment. The same mix of differences that Hume identified in the critic affects everyone.

Questioning the presumption that universality is cognitively necessary and the grounds for universality in an independent, objective world thus leads to a different understanding of judgments of scenic beauty and of taste in general. Any discomfort we may feel from abandoning the quest for universality is the consequence of mistaken expectations, the product of a culture that has misunderstood not just the conclusions of the quest but its very conditions.

Further, it requires us to reconsider the contribution that philosophic inquiry can make in such matters. ${ }^{25}$ Does empirical evidence require that we abandon philosophical claims to objectivity?

At issue here is the question of what evidence is relevant. The history of philosophy displays many instances of grave discomfort over empirical evidence. From Plato to Descartes to the present, philosophers in a rationalistic tradition have too often dismissed empirical data as defective in principle. This is not the place to rehearse the long debate between rationalism and empiricism; it is necessary only to recognise that aesthetic inquiry, grounded necessarily in experience, cannot selectively choose (as Kant did) only that evidence that is compatible with its rationalistic presuppositions. As aesthetics is empirical, it must accommodate empirical data, and philosophical assertions that do not acknowledge such evidence cannot escape being irrelevant. Re-casting our understanding of judgments of taste, we may have to revise our understanding of philosophical aesthetics itself. What, then, can philosophy contribute here?

With its sensitivity to the influence of presuppositions and its sharpened conceptual faculties, philosophical criticism is a powerful tool that has wide applicability. Thus one function of philosophical query is its time-honoured critical one of cleaning out the Augean stables, the purpose of this essay. But aesthetics can also have a constructive function. Comparative aesthetics is one area in which discerning vision can identify resemblances and commonalities among different traditions and take note of irreducible differences. The growing interest in identifying contrasting features in Western and Eastern aesthetics offers a broad brush whose individual strokes may reveal illuminating subtleties ${ }^{26}$ For the past century and more artists have drawn increasingly on non-Western cultures: African sculpture, Javanese music, Aboriginal graphics, Chinese gardens, Japanese film, indigenous 


\section{ARNOLD BERLEANT}

architecture and local literatures. Perhaps our philosophical sensibilities can be enriched as our aesthetic ones have been.

This variability, far from being a shortcoming, actually provides a rich range of data ripe for inquiry by aestheticians, as well as by sociologists, psychologists, historians and anthropologists of art. Aesthetics is a field whose subject is the endlessly varied and complex domain of human experience, where scholars and scientists can acknowledge, respect and study the varieties of the aesthetic without prejudice. How varied are the standards within and among different cultures? What similarities do they possess and how do they differ? How have they changed over time and from outside influences? What significance do the answers to these questions have to the cultures in which these standards arise? Can we identify the varied influence of biological commonalities and of the cultural appropriation of genetic predispositions? Are the structure and course of appreciative experience similar among individuals and cultures? Scenic beauty provides a vivid test for the variability of these judgments. And while we end with more questions than we started with, there is a significant difference: these questions can, in principle, be answered.

\section{NOTES}

${ }^{1}$ Nicolson (1963) quotes John Evelyn's Diary from 1644, in which he writes about the Alps 'which now rise as it were suddenly, after some hundred miles of the most even Country in the World, and where there is hardly a stone to be found, as if nature had swept up the rubbish of the Earth in the Alps, to forme and cleare the Plaines of Lombardy'. Compare this to Thoreau: 'What is a horizon without a mountain.' Journal, 2:57.

${ }^{2}$ See Carlson 1977. He argues that 'quantifying scenic beauty may be, even if possible, neither as useful nor as straightforward as much of the current work in environmental aesthetics would lead us to believe' (p. 131). Although the terms and frame of Carlson's discussion differ from those of this paper, our conclusions are compatible.

${ }^{3}$ Hume [1961], p. 6.

${ }^{4}$ Loc. cit.

${ }^{5}$ Hume's characterisation of a 'true judge' is a person who possesses 'strong sense, united to delicate sentiment, improved by practice, perfected by comparison, and cleared of all prejudice....' op. cit., p. 17.

${ }^{6}$ Op. cit., passim.

${ }^{7}$ Immanuel Kant, Critique of Judgment, §1.

${ }^{8}$ Op. cit., p.19. 


\section{RECONSIDERING SCENIC BEAUTY}

${ }^{9}$ James 1892, 329.

${ }^{10}$ Wang Heng Chen, 'On the Beauty of Nature', unpublished manuscript, Wuhan University, 1996, p. 15.

${ }^{11}$ Zhuang-zi, the most famous Taoist after Lao-tse.

${ }^{12}$ Werner Heisenberg (1958). Quoted by Macaulay, Access Index \# 659).

${ }^{13}$ Alexander Gottlieb Baumgarten, Aesthetica (Frankfurt a. O., 1750), Vol. I.

${ }^{14}$ Berleant 2010.

${ }^{15}$ Bourdieu 1984, p. 6.

${ }^{16}$ Ibid., p. 493. Nietzsche may have been making a similar point about Kant: 'Kant wanted to prove in a way that would dumbfound the common man that the common man was right: that was the secret joke of this soul. He wrote against the scholars in favour of the popular prejudice, but for scholars and not popularly.' Friedrich Nietzsche, The Gay Science, $§ 193$.

${ }^{17}$ Ibid., pp. 491-500.

${ }^{18}$ Armstrong 1971; 1981.

${ }^{19}$ First developed in Berleant 1970a.

${ }^{20}$ I have discussed this work more extensively in Berleant 2010, chs. 1-4.

${ }^{21}$ Cf. Beardsley 1958.

${ }^{22}$ Cazeaux 2000, iv-vii.

${ }^{23}$ See Berleant 1991; 1992; and subsequent publications.

${ }^{24}$ Wittgenstein $1958,88 \mathrm{e}, \S 241$. The text here is, "'So you are saying that human agreement decides what is true and what is false?'-It is what human beings say that is true and false; and they agree in the language they use. That is not agreement in opinions but in form of life.' Quoted by Cooper 2006, 112.

${ }^{25}$ In a similar critique of disinterestedness, Bourdieu noted that

'[e]mpirical' interest enters into the composition of the most disinterested pleasures of pure taste, because the principle of the pleasure derived from these refined games for refined players lies, in the last analysis, in the denied experience of a social relationship of membership and exclusion.... [ Positions regarded as inferior are] stigmatized as 'empiricism' or 'historicism' (no doubt because they threaten the very existence of philosophical activity).... op. cit., p. 499.

Bourdieu sees the hierarchy of taste, from vulgar to refined, as reflecting the distinctions of social class, and the intellectual apparatus elaborating and justifying those distinctions as embodying the very same class distinctions. Aesthetics, and philosophy more generally, he claims, are not free intellectual inquiry but are class-prejudicial from the start. Philosophy itself embodies the distinctions that mark social relations in the normativity of its own distinctions.

In short, the philosophical sense of distinction is another form of the visceral disgust at vulgarity which defines pure taste as an internalised social relationship, a social relationship made flesh, and a philosophically distinguished reading of 


\section{ARNOLD BERLEANT}

the Critique of Judgment cannot be expected to uncover the social relationship of distinction at the heart of a work that is rightly regarded as the very symbol of philosophical distinction. op. cit., pp. 499-500.

I made a similar critique of the history of ethical theory in Berleant $1970 \mathrm{~b}$.

${ }^{26}$ Cf. Sasaki 2010.

\section{REFERENCES}

Armstrong, Robert Plant 1971. The Affecting Presence: An Essay in Humanistic Anthropology. Urbana: University of Illinois Press.

Armstrong, Robert Plant 1981. The Powers of Presence: Consciousness, Myth, and Affecting Presence. Philadelphia: University of Pennsylvania Press.

Beardsley, Monroe C. 1958. Aesthetics: Problems in the Philosophy of Criticism. New York: Harcourt, Brace \& World.

Berleant, A. 1970a. The Aesthetic Field: A Phenomenology of Aesthetic Experience. Springfield, Ill.: C. C. Thomas. Second (electronic) edition, with a new Preface (2000) <http://cybereditions.com/spis/runisa/dll?SV:cyTheBooksTmp>.

Berleant, A. 1970a. 'The social postulate of theoretical ethics', Journal of Value Inquiry IV(1): 1-16.

Berleant, Arnold 1991. Art and Engagement. Philadelphia: Temple University Press.

Berleant, Arnold 1992. The Aesthetics of Environment. Philadelphia: Temple University Press.

Berleant, Arnold 2010. Sensibility and Sense: The Aesthetic Transformation of the Human World. Edinburgh: Imprint Academic.

Bourdieu, Pierre 1984. Distinction: A Social Critique of the Judgement of Taste. Cambridge, MA: Harvard University Press.

Carlson, Allen 1977. 'On the possibility of quantifying scenic beauty'. Landcape Planning 4: 131-172

Cazeaux, Clive (ed.) 2000. The Continental Aesthetics Reader. London and New York: Routledge.

Cooper, David E. 2006. A Philosophy of Gardens. Oxford: Clarendon Press.

Hume, David [1961]. 'Of the Standard of Taste', in Of the Standard of Taste and Other Essays (Bobbs-Merrill).

James, William 1892. Psychology. Holt.

Nicolson, Marjorie Hope 1963. Mountain Gloom and Mountain Glory: The Development of the Aesthetics of the Infinite. New York: W.W. Norton.

Sasaki, Ken-ichi 2010. Asian Aesthetics. Kyoto: Kyoto University Press.

Wittgenstein, Ludwig 1958. Philosophical Investigations. Oxford: Blackwell. 